\title{
On Image Schemas of Comparatives in English and Chinese
}

\author{
Li Yan \\ School of Foreign Languages, Yan'an University \\ Yan'an, Shaanxi, China \\ 309485667@qq.com
}

\begin{abstract}
Comparative is one of the basic semantic categories and its representation varies. Previous researches mainly focus on certain syntactic constructions, but systematic studies on comparative category are scarce. English and Chinese schematic representations are observed in this paper. We find that: 1) there are action schema, location schema, goal schema, sequence schema, polarity schema and particle schema as to English and Chinese comparative representations; and among these six schemas; 2) some represent dynamic events while others represent static ones; 3 ) some schemas are basic while some others are evolved via grammaticalization; 4) some schemas are blended and the mechanism of blending needs further investigation.
\end{abstract}

Keywords-Comparative; Image Schema; English; Chinese

\section{INTRODUCTION}

Grammatical studies on comparatives mainly work within the framework of structuralism, universal grammar or language typology. Prototypical comparatives, for a long time, are the focus of comparative studies. According to cognitive linguistics, differences among members of a category occur along the scale of degree, and they work as a category under the mechanism of family resemblance [1]. It is partial to pay much attention to prototypical comparatives, which fails to sketch a whole picture of comparative category and show differences among members of a certain category. Therefore, we attempt to investigate the cognitive image schemas in English and Chinese comparatives and find some universal laws in the representations of comparatives.

\section{IMAGE SCHEMA}

Image schema is a key term in cognitive linguistics. Johnson (1987: xiv), Gibbs \&Colston (1995:349) and Oakly (2007:214-235) defined this term with cognitive embodiment, which is greatly related to language representation. $\mathrm{Li}$ reviewed previous elaborations on image schema and presented the design features of image schema as the following:

Image schema is an abstract structure which is embodied in the interaction between human beings and the outside world it is a skeleton which shares some common characteristics of human activities; it is as untouchable and unseeable as a representation of one's mind; it occurs again and again in human activities; it is employed in organizing and correlating people's experiences; it originates from human experiences and restructures human's abstract concepts by being mapped onto human conceptualization [2].

TABLE I IMAGE SCHEMA

\begin{tabular}{|c|c|c|}
\hline TYPE & $\begin{array}{l}\text { SUB- } \\
\text { TYPE }\end{array}$ & IMAGE SCHEMA \\
\hline \multirow{2}{*}{ I } & $\mathrm{a}$ & $\begin{array}{l}\text { CONTAINMENT/ CONTAINER, } \\
\text { PATH/SOURCE-PATH-GOAL, LINK, } \\
\text { PART-WHOLE, CENTER-PERIPHERY, } \\
\text { BALANCE }\end{array}$ \\
\hline & $\mathrm{b}$ & $\begin{array}{l}\text { the FORCE schemas: ENABLEMENT, } \\
\text { BLOCKAGE, COUNTERFORCE; } \\
\text { ATTRACTION, COMPULSION, } \\
\text { RESTRAINT, REMOVAL, DIVERSION }\end{array}$ \\
\hline \multirow[t]{2}{*}{ II } & a & $\begin{array}{l}\text { CONTACT, SCALE, NEAR-FAR, } \\
\text { SURFACE, FULL-EMPTY, PROCESS, } \\
\text { CYCLE, ITERATION, MERGING, } \\
\text { MATCHING, SPLITTING, OBJECT, } \\
\text { COLLECTION, (MASS-COUNT), } \\
\text { (SUPERIMPOSITION) }\end{array}$ \\
\hline & $\mathrm{b}$ & UP-DOWN, FRONT-BACK \\
\hline \multirow[b]{2}{*}{ III } & $\mathrm{a}$ & $\begin{array}{l}\text { INANIMATE MOTION, ANIMATE } \\
\text { MOTION, SELF MOTION, CAUSED } \\
\text { MOTION (Mandler 1992: 593-596), } \\
\text { LOCOMOTION (Dodge \&Lakoff 2005) }\end{array}$ \\
\hline & $\mathrm{b}$ & $\begin{array}{l}\text { EXPANSION (Turner 1991: 171), } \\
\text { STRAIGHT (Cienki 1998), } \\
\text { RESISTENCE (Gibbs et al. 1994:235), } \\
\text { LEFT-RIGHT (Clausner\& Croft } \\
\text { 1999:15)... }\end{array}$ \\
\hline
\end{tabular}

(A revised table of Li, 2008: $191^{[3]}$ )

\section{TYPES OF REPRESENTING COMPARATIVES}

Early language typology classified languages in terms of the order of subject, object and verb, which is commonly known as SVO, SOV and VSO languages. Greenberg (1963) formulated some implicational universals of $\mathrm{VO}$ languages and OV languages from 30 sample languages [4]. Comparatives in different samples share three common 
parameters as marker, standard and adjective. According to linear investigation of parameters on the basis of semantic considerations, VO languages follow the order of adjectivemarker-standard, while OV languages follow standardmarker-adjective. However, Dryer (1991) extended Greenberg's samples to 68 languages and found that adjective and standard are critical in linear arrangement [5]. Regarding adjective and standard as the most important parameters in comparatives across languages, Dryer concluded that VO languages follow adjective-standard order, while OV language the standard-adjective order.

Stassen (1985:24) pointed out that comparatives in natural languages have the semantic function of assigning a graded position on a predicative scale to two (possibly complex) objects [6]. Six types of comparatives are summarized from 110 sample languages: SEPERATIVE, ALLATIVE, LOCATIVE, EXCEED, CONJOINED and PARTICLE. Matching between linear order and semantic link varies across the said six types, for instance, three or more participants are required for some comparatives, while two clauses are required in some other comparatives.

Most comparative structures in the languages of the world are derived from a limited number of conceptual source structures. Heine (1997:110) hold that comparative constructions are based on propositions involving five elements: CPMPAREE, PREDICATE, DEGREE MARKER, MARKER OF STANDARD, and STANDARD [7]. The employment of degree marker (D) in different languages is diverse. Languages without D include Telugu, Japanese, Eskimo, etc. Languages with optional D include Yurok, Malagasy, Kui, Coptic, etc. Languages with obligatory D include English, German, French, Russian, etc. Therefore, it is not feasible enough to classify comparatives in terms of degree marker.

Variants of comparative representation can be classified into absolute comparatives and relative comparatives. For absolute comparatives, the gradable scale of two entities are ordered according to semantic entailment, of which one is positively attributed. Positive comparatives apply lexical representation to assignment of attribute scales. The degree of one entity exceeds the other one in positive comparative.

To sum up, literatures on comparative representations show the following trends in linguistic studies. First, most attention are paid to comparatives with formal marks, and studies on comparatives without markers are scarce, such as word typology studies in Greenberg (1963), Dryer (1991, 1992) and positive vs. negative distinction in Kennedy (2005) [8]. According to Markedness Theory, the marked forms stand out as unusual or difficult, contrasting with a more common or regular form. The dominant default or minimum-effort form is known as unmarked, while the opposite one is marked. In linguistic representation, unmarked forms are commonly and widely applied, and they merit detailed and scientific investigation. Second, the mappings between form and meaning are multiple in matching across world languages, so are the representations of comparatives. Most recent studies show no diversity in form-meaning matching. Stassen's attempts, avoiding isolated focusing on grammatical forms, are basically classification among different forms, which is quite feasible in analyzing Chinese syntactic-semantics counterparts. Third, the linear representation of comparatives includes a comprehensive consideration of word order, morphology as well as clause type. However, taking word order and clause type into account is only one way for representation. We are going to consider as more possibilities as we could to explore different representations from the perspective of cognitive image schemas in this paper.

\section{IMAGE SCHEMA REPRESENTATION OF COMPARATIVES}

Comparison is one of the basic ways for humans to know about the world, and it is also part of human experiences. It is inevitable to capture the feasible references and compare/contrast them with the entity we are trying to construe. Whenever there is gradable degree along the scale there is potential to be represented by comparatives. The process and consequence of comparison/contrast are mapped as comparative constructions onto language, which are cognitively recognized as image schemas with embodiment.

The interaction between form and meaning has long been the focus of modern linguistics, although the diction of this well-known ties varies across different linguistic paradigms. SS (surface structure) and DS (deep structure) are two alternative terms initiated by Noam Chomsky in Transferredgenerative Grammar. SFL (Systematic Functional Linguistics), founded by M.A.K. Halliday, proposed that language is a system in which meanings form an optional network potentials. Constructions arise with process of realization for the potential of each step in SFL theory. Language topologist William Croft (2001) regarded form-meaning relationship as an encoding process [9]. Talmy (2102:21) hold that a language could be conceived having only a single system, under which there are two subsystems: grammatical and lexical [10]. They have distinct semantic functions: the grammatical elements determine the structure of the cognitive representation; while the lexical ones together contribute the majority of its content. Thus, the lexical elements can be expressed by some grammatical elements, and grammatical elements sometimes can be expressed by lexical ones. From this multiple mapping in semantic representation, two positions can be postulated: the conceptual material either be specified grammatically or lexically.

From the perspective of language typology, every language has its mechanism for representing comparatives, as Graziano-King (1999:19) noted, "Languages vary along a number of dimensions with respect to how they encode comparison. [11]" The variation lies in two aspects: the linear order of elements for comparative meaning varies across languages; and different languages adopt various elements for representation, such as word order, grammatical function, morphology, case marking, etc.

Under the perspective of cognitive linguistics, we assume that English and Chinese comparatives share similar cognitive mechanism. Comparatives in these two languages all arise from limited image schemas: action, location, goal, sequence, polarity and particle. They are elaborated as follows: 


\section{A. Action Schema}

Action schema defines comparatives as a process, in which an agent and an object are involved. Generally speaking, there are at least three lexical elements in a comparative, comparer, compare and result. As for action schema,comparer is deemed as one type of agent which functions as subject of the sentence. The predicate employs transitive verbs which depict the material process. The object is realized by comparee. This schema focuses on the core sense of comparative construction, without visible degree marker and standard.

(1) His ambition outran his ability.

(2) Demand for fish this month exceeds supply.

(3) The beauty of the scenery surpassed all my expectations.

(4) She far transcends the others in beauty and intelligence.

Action schema characterizes with a predicative transitive verb, semantically entailing both [+behavior] and [+consequence], and substantial entity or abstract concept can be employed as standard of comparison. The above instances show "S+V+O" order, with transitive verb as the predicate, representing the agent's activity. The predicate conflates consequence of comparison, such as "outran", "exceed", "surpass" and "transcend". The action schema is applied in Chinese comparative construction, such as "guo/过 (exceed)" and “chao/超 (exceed)”.

\section{(5) 狡捷过猿猴,勇剽若豹螭.(曹植白马篇)}

(6) 由也好勇过我,无所取材. (论语·公冶长)

(7) 泽庞洪,年逾耆荎观光踊,远超五老首曹松.(二十五 史·清史稿)

Transitive verbs represented by image schema of action in Chinese comparative are mostly disyllabic words with the sense of "exceed".

\section{B. Location Schema}

Spatial location is highly embodied in human experiences. Some Chinese words express body parts via spatial location, such as “mianqian (面前)”, “shenhou (身后)”, “toushang (头 上)”, “jiaoxia (脚下)”, etc. Lakoff (1987) includes some basic image schemas by way of spatial location, such as "up-down", "front-back", etc [12]. In location schema, comparer and comparee are construed as two entities with locational distinction of "up-down" or "front-back".

(8) Galileo's ideas were well in advance of the age in which he lived.

(9) The temperature has been above the average recently.

(10) London is about five hours ahead of New York.

(11) Last year, the country's gold production rose by 7.15 percent to 240.08 tons, behind South Africa, Australia and the United States.
Spatial allocation of one entity is described by another entity in location schema. According to gestalt theory, the comparer is the figure, while the compare is the ground, and the consequence of comparison shows the characteristic of figure with respect to the ground. The two entities involved reveal the relative position

(12) 他(郭嵩奉)对西洋的认识远在李鸿章之上.

(13) 西汉末年,丞相更名大司徒,其权力、位次都在大司 马之下.

\section{(14) 主语在宾语的前面.}

The location schema in Chinese employs the construction of "zai (在)+location" in representing differences along the scale. The consequence of comparison conflates with locational preposition phrase.

\section{Goal Schema}

The comparee (standard) is encoded as directional participant, representing by allative, benefactive or dative. ${ }^{[7]}$ This schema shows the advantages of comparer over the comparee. In English, goal schema is encoded as "superior/inferior to". For instance,

(15) Animals are not inferior or superior to humans; we are only different.

(16) My brother is senior to me by two years.

(17) In cooking quality of dehydrated foods are usually superior to sun-dried counterparts

(18) Modern music is often considered inferior to that of the past.

As a preposition, "to" refers to the object of "facing" in English and directs to goal of activity, such as "point to", "turn to", "rise to". In Chinese, " $y u($ 于)" is a semantic counterpart of English "to". For instance,

(19) 冰,水为之, 而寒于水. (荷子.劝学)

(20) 是故弟子不必不如师,师不必贤于弟子.(韩愈师说)

\section{(21) 债券的流通性强于股票的流通性.}

The construction of "consequence+ ' $y u$ "' is widely used in old Chinese and modern Chinese. However, "consequence" in Chinese is highly restricted - phonetically, it should be monosyllabic Chinese word.

\section{Sequence Schema}

Sequence schema in comparatives shows strong order in linear arrangement. The prototypical location schema showcases spatial relationship, while sequence schema represents chronological order. Two successive activities or states are commonly involved in sequence schema, which is mapped as two successive predicates and marked by connectives expressing time. The typical English comparative entails sequence schema. Andersen(1983:130)holds that construction " $\mathrm{X}$ is $\mathrm{Y}$-er than $\mathrm{Z}$ "can be dated back to construction " $\mathrm{X}$ is $\mathrm{Y}$-er, then $\mathrm{Z}$ is $\mathrm{Y}$ ", in which "than" is 
historically evolved from "then" [13]. Gonzalez-Diaz (2008) investigated "than" diachronically and confirmed the evolvement and divergence between "than" and "then" [14]. Li Yan (2015) discovered the dual function of "than". The preposition "than" introduces comparee, and the conjunction "than" introduces number or classifier phrases [15]. Sequence schema also exists in Chinese comparatives, such as the following:

(22) 十月的时候,有 “中国互联网先驱”之称的瀛海威 便出场了,紧随其后中国万网也开通了.

(23) 按照文德尔班的说法, $\cdots \cdots$, 首先是宇宙论时期,其次 是人类学时期,第三个就是到了柏拉图的体系化的时期.

The consequence of comparison in sequence schema is inferred from the chronological order, so this schema is not as typical as the previous ones.

\section{E. Polarity Schema}

Andersen(1983:108)noted that semantically opposite elements can be arranged in one sentence to express a special comparative construction. ${ }^{[13]}$ In this polarity schema two semantically divergent clauses are combined into one sentence. Stassen(1985:38)concluded this construction as "A is p,but B is q." ${ }^{\left[{ }^{6]}\right.}$ Both English and Chinese share this schema, such as:

(24) Thomas is rich, but Simon is poor.

(25) 扁担长,板發宽.

(26) Thomas is rich, but Simon is not rich.

(27) 有些父母学历高,但文化素质并不高.

\section{F. Particle Schema}

Particle schema arises from some morph-syntactic grammaticalization. Heine $(1997: 120)$ noted that it was not easy to trace the process of restoring the evolving path, because the underlying grammaticalizaiton this schema was also involved in evolution [7]. Nevertheless, most languages across the word, more or less, adopt particle schema to represent comparatives. A grammaticalized particle is necessary for particle schema, such as English "than", Chinese "bi", French "que" and Latin "quam".

The marker "than" in modern English is evolved from sequential "then". Etymology has confirmed "than" and "then" are derived from the same origin, which gradually diverged from each other in the 18th century. The Chinese particle "bi" was evolved from action schema. This marker in old Chinese was a verb. However, with the uprising and evolution of the new component "W" which developed various types of consequence, this particle was finally evolved as a functional marker. Therefore, English and Chinese particles in comparatives show no hints of similar evolution, and this situation is universal across world languages.

\section{CONCLUSION}

Comparatives showcase diverse diagrams for representing image schemas. Both English and Chinese employ action schema, location schema, goal schema, sequence schema, polarity schema and particle schema. The action schema draws dynamic ties between the two entities involved in a comparison, while the other schemas show static ties. Thus, schema representations of comparatives vary along dynamic and static diagrams. What's more, more than one schema can be employed in both English and Chinese comparatives. To sum up, typological characteristics can be obtained from comparative representations. Complex as it is, schema evolution and fusion need further investigation.

\section{ACKNOWLEDGMENT}

This article is sponsored by MOE (Ministry of Education in China) Humanities and Social Sciences Foundation, No.15 YJC740039; and by 2017 Humanities and Social Sciences Foundation of Shaanxi Educational Committee, No.17JK0838.

\section{REFERENCES}

[1] Ungerer\&Schmid, An Introduction to Cognitive Linguistics [M]. Beijing: Foreign Language Teaching and Research Press, 2008.

[2] Li Fuyin,An Introduction to Semantics [M]. Beijing: Peking Univeraity Press, 2007, pp.81.

[3] Li Fuyin,An Introduction to Cognitive Linguistics [M].Beijing: Peking Univeraity Press, 2008, pp.191.

[4] Greenberg, J.H., Some Universals of Grammar with Particular Reference to the Order of Meaningful Elements [A]. In Greenberg,J.H.,Universals of Language[C]. Cambridge: MIT Press, 1966

[5] Dryer Matthew, SVO language and the OV:VO typology [J].Journal of Linguistics, 1991(27-2), pp.443-482.

[6] Stassen Leon, Comparison and Universal Grammar [M]. Oxford: Basil Blackwell, 1985.

[7] Heine Bernd, Cognitive Foundations of Grammar [M]. New York: Oxford University Press, 1997.

[8] Kennedy\& Louise MacNally, Scale Structure, Degree Modification, and the Semantics of Gradable Predicates [J]. Language,2005, pp.345-381.

[9] Croft William \& Cruse Alan, Cognitive Linguistics [M]. Cambridge: Cambridge University Press, 2004, pp.45.

[10] Talmy Leonard,Toward a Cognitive Semantics (Volume II): Typology and Process in Concept Structuring, [M]. Beijing:Foreign Language Teaching and Research Press,2012

[11] Graziano-King Janine, Acquisition of Comaparative Forms [D]. PhD Dissertation. City University of New York Graduate, 1999, pp.19.

[12] Lakoff George,Women, Fire and Dangerous Things: What Categories Reveal About the Mind[M]. Chicago: University of Chicago Press, 1987, pp.282-283.

[13] Anderson, Word Order Typology and Comparative Constructions [A]. Studies in the Theory and History of Linguistic Science [C]. Amsterdam: John Benjamins, 1983.

[14] Gonzalez-Diaz Victoria, English Adjective Comparison [M]. Amsterdam/ Philadephia: John Benjamins Publishing Company, 2008.

[15] Li Yan,On Grammaticalization of Comprative Markers in Chinese and English, [J] Foreign Language Teaching,2015(4), pp.41-44. 